\title{
Las composiciones de extranjeros en la Nueva España, 1595-1700
}

\author{
Eleonora Poggio \\ Doctoranda \\ Universidad Pablo de Olavide \\ Departamento de Historia Moderna \\ Ctra. de Utrera, km. 1 \\ 41013, Sevilla, España \\ eleonora.poggio@gmail.com
}

Fecha de recepción: 23/04/2011

Fecha de aceptación: 15/12/2011

\begin{abstract}
RESUMEN
Al encontrarse con una hacienda exhausta a principios de la década de 1590, Felipe II buscó obtener recursos económicos por distintos arbitrios extraordinarios en los virreinatos americanos. Uno de ellos fue la composición de extranjeros. La composición ha sido entendida en términos de legalización y regularización de ilegales en las Indias. Este artículo propone que era una penalización que formaba parte de un proceso más amplio por el cual el rey administraba su gracia. Se analiza su origen, las transformaciones, los problemas y las soluciones que los servidores reales encontraron para su aplicación, así como la recepción y significado que tuvieron entre la población extranjera en la Nueva España entre 1595 y 1694.
\end{abstract}

Palabras clave: extranjeros, composición, arbitrios, penalización.

\section{The composiciones for foreigners in New Spain, 1595-1700}

\begin{abstract}
In the early 1590s, Philip II of Spain recognized that the royal treasury was exhausted. In an effort to recoup monetary resources, he imposed several taxes in the American viceroyalties. One of them was the composición (settlement) for foreigners. The composición has been interpreted as a way of legalization and regularization of illegal foreigners. We argue instead that composición was a penalty, executed by the king in order to distribute Royal Patronage. We analyze its origins and transformations, as well as the problems experienced by the king's servants, and the solutions they found for its application in Mexico between 1595 and 1694. Finally, we examine how the composición was received and the impact it had on foreigners.
\end{abstract}

Key words: foreigners, taxation, composición (settlement), penalization. 


\section{INTRODUCCIÓN}

A finales de 1580, Felipe II realizó un balance financiero y se encontró con una hacienda exhausta para solventar las guerras en los Países Bajos, con Francia e Inglaterra, los costes de la Casa Real y de la construcción del Escorial así como el pago de las deudas atrasadas contraídas con sus acreedores. El grave estado en que se encontraba el erario obligó al monarca y a sus consejos a buscar nuevos medios para obtener ingresos y aligerar los gastos de forma que pudieran cubrirse las necesidades y compromisos de la monarquía a corto plazo. Desde 1589, el rey giró instrucciones al Consejo de Indias para que negociara con el Consulado de Mercaderes la repartición de las expensas de la armada que acompañaba a la escolta de la Carrera de Indias y que hasta entonces corría totalmente por su cuenta. A finales de 1591, ambas partes llegaron a un acuerdo que resultó en la firma del primer asiento sobre el cobro de la avería por cuatro años y la construcción de una armada de diez galeones que se sumarían a los ya existentes ${ }^{1}$. Tanto la fábrica como el mantenimiento de la armada se sufragarían con fondos mixtos extraídos del cobro del impuesto y de otros ramos de la hacienda, lo cual significaba un alivio para las finanzas del rey, pero el problema no quedaba completamente solucionado.

Para obtener el capital restante, el Consejo ideó una serie de gravámenes y recaudaciones extraordinarias a imponerse en los territorios indianos mismos que fueron aprobados por la Junta Grande de Hacienda, reunida en sesión permanente desde el verano de ese año ${ }^{2}$. Las medidas, remitidas a las principales autoridades políticas, judiciales y civiles de los virreinatos en forma de Instrucciones en noviembre de 1591, mandaban implementar el servicio de indios, la venta de algunos oficios públicos (regimientos, alferazgos y alguacilazgos mayores), la habilitación de mestizos para obtener cargos, el pago de alcabalas a toda la población exceptuando a los indios, la incorporación de las salinas y el beneficio del agua salada a la Real Hacienda para su arrendamiento, así como la composición de tierras y de extranjeros ${ }^{3}$.

La composición fue el procedimiento por el cual más extranjeros tuvieron contacto con las autoridades reales en las Indias, a pesar de esto su estudio hasta ahora ha sido fraccionado y casi reducido al área del virreinato peruano. Se han explicado como un método utilizado por la Corona para legalizar o regularizar a los extranjeros que se encontraban de forma ilícita en las colonias y que cumplían con ciertos requisitos. Se ha argumentado, así mismo, que era una opción que permitía al ilegal remediar su condición y lograr la integración y el arraigo en las sociedades locales ${ }^{4}$.

\footnotetext{
${ }^{1}$ Caballero JuÁrez, José Antonio: El régimen jurídico de las armadas de la Carrera de Indias siglo XVI y XVII, México, Universidad Nacional Autónoma de México, 1997, pp. 300-315; SÁnCHEz-Bella, Ismael: La organización financiera de las Indias (siglo XVI), Escuela de Estudios Hispano-Americanos-CSIC, Sevilla, 1968, pp. 47-50 y 202-256.

2 Archivo General de Indias (en adelante AGI), Indiferente, 433, L. 2, f. 50-50v. Carlos Morales, Carlos Javier de: Felipe II: el imperio en bancarrota. La Hacienda de Castilla y los negocios financieros del Rey Prudente, Madrid, Dilema, 2008, p. 259. La armada en cuestión terminó siendo la Armada del Mar Océano integrada por diez galeones y seis pataches con base en Lisboa. Ver ScHÄFER, Ernesto: El Consejo Real y Supremo de las Indias, España, Junta de Castilla y León-Marcial Pons, 2003, vol. 2, pp. 341-343.

3 AGI, Indiferente, 433, L. 2, f. 50-50v.

4 Rodríguez Vicente, María Encarnación: «Los extranjeros en el reino del Perú a finales del siglo XVI» en De
} 
Sin embargo, en un estudio reciente, Tamar Herzog ha demostrado como la integración en las sociedades de antiguo régimen en España y América era un proceso que pasaba por múltiples mecanismos locales y no a través de definiciones exactas sobre la extranjería. El alcance y la aplicación de la naturaleza jurídica, por encontrarse en proceso de construcción, era más bien dúctil y dependía de las negociaciones, pactos y reciprocidades vigentes en cierto momento y en distintas circunstancias, sobre todo durante los siglos XVI y XVII. Se carecía, por tanto, de categorías legales formales para definir la pertenencia de los individuos a una comunidad de vecinos o súbditos ${ }^{5}$.

Este artículo propone que las composiciones no cumplían una función reguladora ni facilitaban la integración, sino que eran un elemento dentro de la cadena antidoral abierta con el fin de imponer una recaudación extraordinaria a un sector de la población en las Indias y por el cual el rey administraba su gracia. Asimismo, hace un recorrido por las transformaciones que sufrieron en su forma y organización, así como las dudas, problemas y soluciones que encontraron los servidores reales para ponerlas en marcha desde su primera aplicación en 1595 hasta la última registrada en 1694 en el virreinato de la Nueva España. Por último, muestra que, lejos de suponer un beneficio para los extranjeros avecindados en los territorios americanos, la composición significaba una verdadera molestia para la mayoría de ellos, aunque algunos también aprovecharon para obtener beneficios.

\section{EL ORIGEN DE LA IDEA}

En la coyuntura económica de 1590, el secretario de Felipe II, Juan Ruiz, mandó al Consejo de Indias una relación escrita por el capitán Pedro Vivanco para que sus funcionarios "se enteraran de lo que contiene". Vivanco aseguraba que, a pesar de las órdenes prohibitivas en materia de migración, los extranjeros seguían pasando a las Indias donde acumulaban por lo general grandes fortunas, fingían su religión y coadyuvaban con los corsarios y piratas que asolaban las costas americanas. Aunado a esto, las repetidas órdenes de expulsión habían generado una ola de abusos entre los servidores reales, quienes extorsionaban a los extranjeros amenazándolos con la expulsión y decomisando sus bienes sin que nadie, al final, supiera dónde paraba lo recaudado. El capitán recomendaba que se nombraran jueces de comisión desde Madrid para que aprehendieran a los infractores, les confiscaran sus haciendas y las vendieran en almoneda pública. Para atajar el problema que suponía los gastos de expulsión, proponía que el traslado de los extranjeros y de sus bienes se cubrieran

Motes, Maluquer J.: Homenaje a Jaime Vicens Vives, Barcelona, Universidad de Barcelona, 1967, p. 534; MöRNER, Magnus: Aventureros y proletarios. Los emigrantes en Hispanoamérica, Madrid, Mapfre, 1992, p. 18; LAZA ZERóN, María del Carmen: «Inmigrantes clandestinos españoles y extranjeros en Nueva España», Temas Americanistas, 11 (1994), pp. 10-15; Vila Vilar, Enriqueta: Aspectos Sociales en América Colonial. De extranjeros, contrabando y esclavos, Bogotá, Instituto Caro y Cuervo-Universidad de Bogotá, 2001, pp. 1-38; Ortiz DE LA TABLA y Ducasse, Javier: «Extranjeros en la Audiencia de Quito» en Solano Pérez-Lila, Francisco de Paula y Del Pino Díaz, Fermín (coords.): América y la España del siglo XVI, Madrid, CSIC, 1983.

${ }^{5}$ Herzog, Tamar: Vecinos y extranjeros. Hacerse español en la Edad Moderna, Madrid, Alianza Editorial, 2006, pp. 27-204. 
con lo recaudado que calculaba sería "mucho número porque se ganará lo de la guerra. Será también menester para los gastos de Su Majestad que cada día se ofrece en defender la santa fe"6.

Expulsar a los extranjeros de los territorios americanos era una medida ya existente que se ordenaba continuamente pero que tenía poco o nulo efecto en la práctica. Así, por ejemplo, el visitador general de la Nueva España, Jerónimo Valderrama, informaba en 1564 como los extranjeros estaban en esas provincias “...tan quietos como si no hubiera provisión que los mandara echar" y diversas autoridades reportaban su imposibilidad de cumplir con las disposiciones porque eran muchos y estaban dispersos a lo largo y ancho del territorio ${ }^{7}$. Sin embargo, en el contexto de urgencia económica en que se encontraba la hacienda en 1590, el contenido del informe de Vivanco asegurando la existencia de un elevado número de extranjeros sin licencia para residir en las colonias que acumulaban grandes fortunas a partir de los bienes patrimoniales del rey, calzaba perfectamente para someterlos a una tasación.

No obstante, el sistema de pactos y reciprocidades en que se basaban las dinámicas sociales en el antiguo régimen, implicaba que por un lado, toda imposición fiscal fuera justa, es decir, que encontrara sus fundamentos dentro del marco jurídico existente para no romper el equilibrio social y por otro, que ofrecieran una retribución dirigida a fortalecer los lazos de lealtad en que descansaba la relación entre el monarca y sus súbditos buscando cerrar el círculo de la economía de la dádiva que por fuerza se abría para obtener los beneficios ${ }^{8}$.

\section{LA CREACIÓN DEL ARBITRIO: EL MARCO JURÍDICO}

Desde prácticamente los inicios de la colonización española en América, existió una marcada prohibición real hacia la migración y el asentamiento de extranjeros en las Indias ${ }^{9}$. Esta exclusión tuvo su sustento en las llamadas Bulas Alejandrinas, otorgadas por el papa Alejandro VI a los reyes Católicos en 1493, las mismas que definieron los derechos exclusivos de Castilla sobre los territorios americanos, así como su obli-

\footnotetext{
${ }^{6}$ AGI, Patronato, 171, N. 1, R. 35 (1590).

7 Cit. por Arregui Zamorano, Pilar: La Audiencia de México según los visitadores, siglos XVI y XVII, México, Universidad Nacional Autónoma de México, 1981, p. 145; Archivo Histórico Nacional (en adelante AHN), Inquisición, leg. 2269 (1573); AHN, Inquisición, leg. 2269, ff. 455-466.

${ }^{8}$ Espanha, Antonio Manuel: La gracia del derecho. Economía de la cultura en la Edad Moderna, Madrid, Centro de Estudios Constitucionales, 1993, p. 154.

9 Konetzke, Richard: «Legislación sobre inmigración de extranjeros en América durante la época colonial», Revista Internacional de Sociología, III-11 y 12 (1945), pp. 269-299; OTs CAPDEQuí, José María: «Los portugueses y el concepto jurídico de extranjería en los territorios hispano-americanos durante el periodo colonial», Congreso de la Asociación Española para el Congreso de las Ciencias. Ciencias históricas, Madrid, 1932, pp. 95-107; GARCíABAQUero, Antonio: «Los extranjeros en el tráfico con Indias: entre el rechazo legal y la tolerancia funcional» en Villar García, María Begoña y Pezzi Cristóbal, Pilar (dirs.): Los extranjeros en la España Moderna, Málaga, Ministerio de Ciencia y Tecnología, 2003, pp. 73-99; Moreno, Ludelino: «Los extranjeros y el ejercicio del comercio en Indias» en Colección de estudios históricos, jurídicos, pedagógicos y literarios, Madrid, C. Bermejo, Madrid, 1936, pp. 364-385; Domínguez OrTiz, Antonio: «Concesión de 'naturalezas’ para comerciar con las Indias», Revista de Indias, XIX-76 (1959), pp. 227-239. El trabajo más exhaustivo sobre la construcción de la naturaleza en la Monarquía Hispánica es de Herzog: op. cit. (nota 5).
} 
gación para evangelizar a las poblaciones originarias. Desde fechas muy tempranas, la Corona se basó en esos privilegios para excluir o penalizar a sujetos cuyo origen territorial o religión se creía ponían en riesgo sus intereses políticos, económicos y doctrinales. De esa forma, se prohibió el paso a las Indias de musulmanes, judíos, herejes, reconciliados con la Inquisición, conversos (1503) y extranjeros (1504), a la vez que se buscó impedir su migración y permanencia en América por varios medios como la expedición de licencias de pasajeros, la visita de navíos para controlar el origen de las tripulaciones y el mandamiento continuo de órdenes de expulsión ${ }^{10}$.

Sin embargo, las medidas no tuvieron mayores resultados prácticos por la falta de recursos humanos, medios económicos y coercitivos para cumplirlas. Así mismo, cualquier intento regulatorio se vio rebasado por el curso natural de las corrientes migratorias abiertas en el espacio Atlántico y Pacífico. En el caso de la Nueva España, el derrumbe demográfico de la población indígena y las necesidades de mano de obra originadas por el desarrollo de la economía colonial favoreció la llegada e incorporación de inmigrantes de todas las latitudes europeas. Este fenómeno se volvió evidente sobre todo a partir de las tres últimas décadas del siglo XVI y las dos primeras del XVII, cuando el aumento del volumen del comercio atlántico (incluyendo la trata de esclavos) requirió más embarcaciones, marinería y soldados, a la vez que permitió la movilización de un mayor número de pasajeros ${ }^{11}$. Desde entonces, encontramos en los virreinatos a un nutrido número de portugueses, genoveses, florentinos, napolitanos, alemanes, franceses, flamencos, griegos y sujetos de otras naciones cuya heterogeneidad étnica parece reflejar a las comunidades de inmigrantes establecidas en los principales puertos de la Baja Andalucía y Portugal en su origen y proporción ${ }^{12}$.

A la par que la Corona buscaba regular el paso de inmigrantes, la propagación de la costumbre castellana que reconocía como naturales a los extranjeros que cumplían con los deberes y gozaban de los privilegios colectivos, facilitó su integración en las comunidades locales indianas como vecinos independientemente de las prohibiciones reales sobre su paso, permanencia y actividad comercial en América ${ }^{13}$. La Corona

\footnotetext{
10 Konetzke: op. cit. (nota 9); Herzog: op. cit. (nota 5).

11 Archivo General de la Nación de México (en adelante AGNM), Reales Cédulas duplicadas, vol. 4, exp. 30, f. 29, 17 de octubre de 1602 .

12 Domínguez Ortiz, Antonio: Los extranjeros en la vida española durante el siglo XVII y otros artículos, Sevilla, Diputación de Sevilla, 1996; IsRaEL, Jonathan: «The Portuguese in Seventeenth Century Mexico», Jahrbuch für Geschichte von Staat, Wirtschaft und Gesellschaft Lateinamerikas, 11 (1974), pp. 12-23; Israel, Jonathan: Razas, clases sociales y vida política en el México Colonial, 1610-1670, México, Fondo de Cultura Económica, 1980; Da Graça A. Mateus, Maria: Portugueses no Peru au tempo da união ibérica, Lisboa, Impresa Nacional-Casa da Moneda, 2005; Poggio, Eleonora: Extranjeros protestantes en la Nueva España. Una comunidad de flamencos, neerlandeses y alemanes 1598-1601 (tesis de licenciatura), México, Universidad Nacional Autónoma de México, 2004; STOLs, Eddy: «Artesanos, mercaderes y religiosos flamencos en el México virreinal», en PÉrEz RosALES, Laura y VAN DER SLUIS Arjen (coords.): Memorias e historias compartidas. Intercambios culturales, relaciones comerciales y diplomáticas entre México y los Países Bajos, siglos XVI-XX, México, Universidad Iberoamericana, 2009, pp. 19-40; Uchmany, Eva Alejandra: La vida entre el judaísmo y el cristianismo en la Nueva España 1580-1606, México, Fondo de Cultura Económica, 1992; GARCíA DE LEÓN, Antonio: «La malla inconclusa. Veracruz y los circuitos comerciales lusitanos en la primera mitad del siglo XVII» en IBARRA, Antonio y Del Valle, Guillermina (coords.): Redes sociales e instituciones comerciales en el imperio español, siglos XVII a XIX, México, Instituto Mora-Universidad Nacional Autónoma de México, 2007, pp. 41-83.

13 Herzog, op. cit. (nota 5); Sánchez Bella, op. cit. (nota 4); Remenería Díaz, Carlos y De la Hera, Alberto: Historia del derecho indiano, España, Mapfre, 1992, pp. 303-307.
} 
tendió a reconocer esta costumbre ${ }^{14}$ y la recogió en dos cédulas fechadas en 1561 y $1562^{15}$ donde aceptaba como naturales de sus reinos a los foráneos que hubieran vivido diez años en los virreinatos, estuvieran casados con naturales, tuvieran bienes raíces y no se dedicaran al comercio. A partir de entonces, la jurisprudencia en que se movían las autoridades reales oscilaba entre esas dos líneas que iban de la completa prohibición a la permanencia de extranjeros en Indias y la indiferencia que favorecía su integración y su eventual naturalización.

Con este marco jurídico disponible, el monarca y el Consejo de Indias (con acuerdo y parecer), encontraron una forma para imponer un arbitrio sobre los extranjeros. Ésta quedó plasmada en dos cédulas incluídas en las Instrucciones que se enviaron a las autoridades americanas en noviembre de 1591. La primera reiteraba la orden de expulsión de todos los territorios americanos de los no naturales de los reinos de Castilla, Aragón, Valencia y Cataluña que se hubieran trasladado sin licencia a ellos en un periodo de cuatro meses. De esta forma se recordaba la afrenta cometida y se refrendaba la validez de la prohibición, es decir, se criminalizaba a un sector de la población, a aquellos extranjeros que no convenían al servicio del rey o de sus provincias. Decidir quiénes entraban dentro de esta categoría y los castigos a imponerse se dejaba a consideración de las justicias locales, quienes contaban con total libertad (por fuero y por derecho) para proceder contra ellos de forma que se proveyera justicia y se persuadiera a otros de violarla ${ }^{16}$.

Pero esta primera cédula también abonaba el terreno para dar paso a otra por la cual el rey administraba su gracia, abriendo así la antidora ${ }^{17}$. Ésta quedaba reservada a aquellos extranjeros que sí convenían a su servicio - tenían caudal suficiente para merecerla- o que por sus vínculos familiares, su provecho a la república o su integración a la sociedad (naturaleza) se considerara resultaría injusto o perjudicial para el orden social que fueran castigados. Movido por esas razones, el monarca les hacía un beneficio, o sea, les obsequiaba su perdón por haber violentado su prohibición de pasar a las Indias sin licencia. Sin embargo, su transgresión conllevaba otra: los territorios americanos eran tierras realengas y acumular caudal sin el beneplácito del rey (la licencia) era lo mismo que hurtar su patrimonio, acto que era tipificado con la confiscación de bienes pero que, por gracia real, se instruyó dirimir a través de una composición, como comúnmente sucedía en estos casos.

La composición era una penalización económica usada comúnmente para alcanzar acuerdos entre partes en crímenes contra la propiedad. El afectado recibía algún bien del agresor dándose por contento y restaurándose así la paz entre ellos. El rey, en su papel de juez supremo y parte ofendida, usó este recurso en múltiples ocasiones para

${ }_{14}$ En las instrucciones dadas a Nicolás de Ovando en 1501 para gobernar la isla Española se le ordenó elaborara una lista con los nombres de los extranjeros que encontrara en ella y los expulsara. Tras remitirse la relación de los foráneos a Castilla, la Corona decidió permitirles su estadía en razón del tiempo prolongado que habían habitado en ellas, aunque ordenó que no se permitiera que nuevos pobladores extraños se avecindaran en ultramar. Ver KonETZKE: op. cit. (nota 9).

${ }^{15}$ AGNM, Reales Cédulas Duplicadas, vol. 30, exp. 1249, ff. 339-342v.; KoneTZKe: op. cit., (nota 9).

${ }^{16}$ AGI, Indiferente, 433, L.2, ff. 49 v. y 64-65.

17 Ver Clavero, Bartolomé: Antidora. Antropología católica de la economía moderna, Milán, Giuffrè Editore, 1991. 
defender su hacienda de sus súbditos en casos de hurto, por ejemplo en la "omisión" de los mercaderes en el pago de alcabalas u otro tipo de derechos ${ }^{18}$. Al ser los territorios indianos bienes realengos, la ocupación de tierras o la monopolización de las aguas superficiales sin contar con una merced, cayó dentro de esta categorización por considerarse que se había beneficiado de recursos que pertenecían a la Corona sin su consentimiento. Esta misma lógica seguía la composición de obrajes, pulperías y pulques en tanto que particulares obtenían ganancias a partir de actividades que requerían licencia del monarca. La composición de extranjeros no fue una excepción en ese sentido pues condenaba la acumulación de caudal en territorio patrimonial del rey sin el beneplácito de su dueño, de ahí que la pena impuesta recayera -en teoríasobre la hacienda que los extranjeros "hubieran adquirido en las Indias" y no antes de desplazarse a ellas ${ }^{19}$.

Determinar qué extranjeros eran merecedores de la gracia, así como la cantidad que debían pagar quedaba, como se verá más adelante, a consideración casuística de las justicias, quienes valoraban distintos atributos del individuo. Sin embargo, como el rey había previamente dado su beneficio, los transgresores quedaban compelidos a devolver el gesto "libremente" y por ello la proporción de dinero que debían pagar quedó consignada en las cédulas como servicio, o sea como una dádiva voluntaria. Por último y para cerrar la antidora, el monarca premiaba ese regalo con una merced por la cual concedía una licencia que suplía la que obviaron pedir en Sevilla y que les permitía "estar, vivir y residir en esas provincias y en las demás partes de las Indias a las que fueran" sin ser molestados por las justicias locales bajo la estricta condición de no ejercer el comercio transoceánico, aunque en este punto también se hicieron excepciones ${ }^{20}$.

La licencia era únicamente irrevocable por el rey. Un buen número de ocasiones los virreyes y oidores de la Audiencia sugirieron al monarca invalidarlas, devolver el dinero cobrado a los beneficiados y expulsarlos del virreinato por las múltiples desventajas que consideraban tenía su presencia en las Indias tanto para el comercio como para la seguridad de los puertos y reales de minas. El monarca se rehusó a anular los privilegios otorgados recordando siempre que se habían dado bajo su juramento regio o $\mathrm{fe} \mathrm{real}^{21}$ y recordó que esa misma consideración debían recibir los extranjeros que por sus años de residencia en los reinos se volvían naturales ${ }^{22}$.

Estamos entonces ante una expresión de la gracia real y su respectivo desenlace antidoral, orden utilizado para alcanzar una recaudación fiscal extraordinaria y botón de muestra de la complejidad del sistema de pactos, reciprocidades y lealtades en que se basaban las sociedades de antiguo régimen.

18 Oliva Melgar, José María: El monopolio de Indias en el siglo XVII y la economía andaluza. La oportunidad que nunca existió, España, Universidad de Huelva, 2004, p. 62.

19 AGI, Indiferente, 433, L.2, f. 49 v., 1 de noviembre de 1591.

20 Ibidem, ff. 50 v. y 64 v.

21 Ver CARrasco Machado, Ana Isabel: «'Por mi palabra y mi fe real...': el papel del juramento regio en el conflicto sucesorio (1468-1480)», en Ribot Garcia, Luis Antonio, Valdeón BaruQue, Julio y Maza Zorrilla, Elena: Isabel La Católica y su época, España, Universidad de Valladolid, 2007, pp. 401-417.

22 AGI, México, 24, N. 26, 4 de octubre de 1599; AGI, México, 29, no. R. 2, 27 de septiembre de 1619; AGI, México, 29, N. 83, 10 de junio de 1622; AGI, México, 29, N. 94, 8 de noviembre de 1622. De la Torre ViLlar, Ernesto: Instrucciones y Memorias de los Virreyes Novohispanos, México, Editorial Porrúa, 1991, p. 383. 


\section{REPARTIENDO LA GRACIA: LAS COMISIONES DE EXTRANJEROS}

La composición fue el procedimiento por el cual más extranjeros llegaron a tener contacto con las autoridades en las Indias. Tan solo en la Nueva España se realizaron por órdenes de la Corona en ocho ocasiones entre 1595 y 1689, aunque su aplicación en casos aislados fue continua durante prácticamente todo el siglo XVII. Se ha señalado anteriormente que la motivación de las composiciones fue la constante precariedad económica de la Hacienda Real. Si bien esto es verdad, en la Nueva España también se efectuaron como secuela de otras acciones tomadas contra los extranjeros en ambos lados del Atlántico ${ }^{23}$. Fue ese el caso de la composición de 1616, que derivó de las pesquisas hechas por junta particular formada por el marqués de Guadalcázar a petición del Consulado de México para expulsar a los mercaderes extranjeros que no cumplieran con los requisitos de la cédula de 1608 y que, a la sazón de la coyuntura de paces, se habían incrementado en el virreinato. El Consejo de Indias respondió a esta iniciativa disolviendo la junta e instruyendo se iniciara un periodo de composiciones ${ }^{24}$. Otro tipo fueron las que se ordenaron por extensión de la guerra económica contra potencias enemigas como las represiones contra franceses de 1625, 1635 y 1674 realizadas en la Península y ordenadas bajo ese mismo nombre durante los dos últimos años también en los virreinatos ${ }^{25}$. Si bien en principio la iniciativa se dirigía únicamente contra los sujetos de esa nación, las denuncias falsas contra otros extranjeros, las excepciones hechas hacia los propios galos u otros factores hacían que la estrategia, diseñada para debilitar las redes comerciales del enemigo en turno terminara discurriendo en composiciones ${ }^{26}$.

Asimismo, en momentos de extrema necesidad de la Real Hacienda, la Corona se reservó esta gracia e hizo suyas propuestas alternativas sugeridas por los virreyes. Sucedió así en 1621, cuando el fin de la Tregua de los Doce Años y la entrada de España a la Guerra de los Treinta Años obligó a Felipe IV a pedir a sus ministros en la Nueva España buscaran arbitrios de donde se pudieran sacar 300.000 ducados. A pesar de la urgencia, las consideraciones del recién llegado virrey Diego Carrillo de Mendoza y Pimentel, marqués de Gelves, sobre la inutilidad generalizada de la población extranjera en las colonias y la poca cantidad de dinero que se había obtenido hasta entonces de ellos a través del arbitrio, convencieron al monarca de no instrumentarlas ${ }^{27}$.

Del mismo modo, en 1619, los oidores de la Audiencia y el virrey marqués de Guadalcázar remitieron sus dudas sobre una nueva cédula en que se mandaba componer absolutamente a todos los extranjeros dándoles además oportunidad de obtener licencia para tratar y contratar en el comercio atlántico. Para no ejecutar lo dispues-

${ }^{23}$ Vila Vilar: $o p$. cit. (nota 4); De la Tabla Ducasse: op. cit. (nota 4).

${ }^{24}$ AGI, México, 28, N. 23, 25 de mayo 1615.

25 AGNM, Hospital de Jesús, L. 450, exp. 4, 28 de junio de 1635; AGI, México, 48, R. 1, N. 10, 24 de enero de 1676. Sobre las represiones en España ver: Alloza APARICIO, Ángel: «Guerra económica y comercio europeo en España, 1624-1674. Las grandes represalias y la lucha contra el contrabando», Hispania, LXV/1, 219 (2005), pp. 227-280.

${ }^{26}$ AGI, México, 48, R. 1, N. 10, 24 de enero de 1676; AGNM, Indiferente Virreinal, Caja 5897, exp. 30; AGNM, Indiferente Virreinal, caja 4802, exp. 35.

27 AGI, México, 74, R. 2, N. 43, L.1, 11 de noviembre de 1621; AGI, México, 29, no. 83, 10 de junio de 1622; AGI, México, 29, N. 94, 8 de noviembre de 1622. 
to, los oidores declararon no poderse poner de acuerdo sobre la interpretación que debía dársele al documento dejando su contenido suspenso por tiempo indefinido ${ }^{28}$. De modo que a la motivación económica deberíamos también añadir la política y la que se considerara más conveniente o práctica tanto para el monarca como para sus ministros en la Nueva España.

Las cédulas mandadas por Felipe II en 1591 dejaban un amplio margen de actuación jurídica a los ministros para cumplir con las instrucciones. Sin embargo, creemos que se enviaron criterios más o menos precisos desde la Península sobre cómo debían organizarse ${ }^{29}$. Esas disposiciones sirvieron como modelo al que se le fueron añadiendo nuevos elementos aprendidos a través de la prueba y el error a lo largo del siglo XVII con el fin de abarcar a un mayor número de población esparcida en el territorio virreinal y optimizar la recaudación ${ }^{30}$.

La tarea se ponía a cargo de una comisión formada específicamente para la ocasión con límites temporales de actuación fijados generalmente en un par de meses, pero que podía prorrogarse dependiendo de la afluencia de los extranjeros. Así, por ejemplo, la primera composición se prolongó en tres ocasiones entre 1596 y 1598 y los jueces provinciales pudieron extenderla por cincuenta días en $1628^{31}$. Los salarios de los comisionados se cobraban, como solía suceder en estos casos, del dinero obtenido por el cobro de los ingresos ${ }^{32}$.

Las comisiones tuvieron distintas formas a lo largo del tiempo. En un principio estuvieron a cargo del oidor más antiguo, un escribano y un alguacil hasta 1622, fecha en que, por sugerencia del Marqués de Gelves, se pusieron bajo la responsabilidad del virrey en turno, quien las despachaba con la ayuda del secretario, el alcalde de corte y un fiscal. En 1641 volvieron a estar a cargo del oidor más antiguo y el fiscal de corte mientras que en 1674 se creó una junta integrada por tres oidores decanos ${ }^{33}$.

A través de un bando se ordenaba a todos los extranjeros que se presentaran ante la comisión en el lapso de entre una y dos semanas. En caso de no apersonarse a tiempo corrían el riesgo de que se les levantaran cargos de "desobediencia y rebeldía" que debían dirimirse en procesos civiles y generalmente resultaban en condenas pecuniarias $^{34}$. Para efectivizar la tarea de los ministros, el bando compelía a todos los vecinos para que denunciaran a los foráneos, bajo amenaza de recibir penas de hasta quinientos pesos en caso de encubrimiento, situación que también se prestaba para realizar

${ }^{28}$ AGNM, Reales Cédulas duplicadas, vol. 4, exp. 147, f. 170, 18 de mayo de 1619; AGI, México, 29, n. 95, 8 de noviembre de 1622 .

${ }^{29}$ El virrey marqués de Guadalcázar utilizó las instrucciones que se le habían dado a Antonio de Maldonado, oidor de la Audiencia y primer juez de extranjeros en 1595, para realizar las composiciones de 1616, que a su vez sirvieron de modelo para las de 1619. A partir de esta última fecha las cédulas tendrán un formato más o menos similar con algunos añadidos. AGI, México, 28, n. 40, 30 de octubre de 1616; AGNM, Reales Cédulas duplicadas, vol. 4, exp. 147, f. 170, 18 de mayo de 1619. Para el caso de Lima ver: AGI, Lima, 33 (1596); ver nota 44.

${ }^{30}$ AGNM, Reales Cédulas duplicadas, vol. 4, exp. 147, f. 170, 18 de mayo de 1619.

31 AGI, México, 71, R.10, n. 133, 28 de abril de 1596; AGNM, Archivo Histórico de Hacienda, vol. 425, exp. 2 y AGNM, Indiferente Virreinal, caja 6083, exp. 32, 6 de septiembre de 1628.

32 AGNM, Archivo Histórico de Hacienda, vol. 425, exp. 2 (1596); AGNM, Indiferente Virreinal, caja 5195, exp. 25, 29 de abril de 1625

${ }_{33}$ AGI, México, 71, R. 9, n. 116, 4 de abril de 1595; AGI, México, 29, n. 83, 10 de junio de 1622; AGNM, Reales Cédulas Originales, vol. 14, exps. 9 y 10, 12 de mayo de 1674.

34 AGNM, Reales Cédulas originales, vol. 233, exp. 4, ff. 61-68v (1641). 
delaciones falsas contra personas de diversos orígenes, incluidos los naturales de los reinos de España y las Indias ${ }^{35}$.

En su primera comparecencia, los foráneos debían presentar una memoria declarando su nombre, nación, vínculos familiares y lugar de residencia así como un inventario de bienes jurado ante notario acompañado de las licencias, cédulas o habilitaciones que tuvieran en su poder. A partir de esta información, el juez de comisión hacía una evaluación e imponía la cantidad a abonarse de inmediato o, de no contar con el capital suficiente, determinaba los plazos en que debía finiquitarse. En este caso, el compuesto debía conseguir fiadores para garantizar que el pago sería cubierto y si residía en la provincia quedaba además obligado a costear el salario diario de la persona que fuera asignada para ir a hacer el cobro en caso de que no se abonara en la fecha acordada ${ }^{36}$.

La suma recaudada se ingresaba en la Real Caja junto con una lista de los compuestos que servía a los oficiales reales para elaborar recibos de pago individuales que eran entregados al alcalde de corte quien, a su vez, los transfería al secretario de corte para que el virrey, después de darles el visto bueno, entregara a cada extranjero la licencia que les autorizaba a residir en las Indias sin ser molestados ${ }^{37}$. Los totales abonados en las cajas provinciales eran enviados a la de México desde donde todo lo recaudado se remitía, por instrucción explícita del rey, por cuenta aparte a la Casa de la Contratación de Sevilla junto con una copia de los llamados "libros de extranjeros" que contenían los datos de los compuestos y las cantidades que habían pagado ${ }^{38}$.

Sin embargo, el hecho de contar con ese documento no eximía al foráneo de comparecer ante las autoridades si se ordenaban nuevas composiciones. En ese caso, debía manifestarse con una "solicitación", es decir, un documento donde incluía su nombre, naturaleza y vecindad, declarando haber comparecido previamente junto con la licencia que así lo acreditaba, la cual era apostillada dándose fe que el portador también había cumplido en esa ocasión ${ }^{39}$.

A diferencia del Perú, donde desde la primera ocasión se nombraron a varios oidores para realizar las primeras composiciones, en la Nueva España se designó únicamente a uno para atender todo el territorio de la Audiencia de México. En la Nueva Galicia no comenzaron a realizarse sino hasta 1607, y la Capitanía de Yucatán no parece haber recibido entradas por este efecto hasta $1632^{40}$.

35 AGI, México, 71, R. 9, n. 116, 4 de abril de 1595; AGNM, Indiferente Virreinal, caja 6705, exp. 70 (1684); AGNM, Indiferente Virreinal, Caja 5897, exp. 30 (1694).

36 AGI, México, 71, R. 10, n. 133, 28 de abril de 1596; AGI, Lima, 570, f. 252v; AGNM, Reales Cédulas Duplicadas, vol. 50, exps. 209-255 (1625). Rodríguez Vicente: op. cit. (nota 4), p. 534.

37 El depositario de las composiciones de extranjeros, Diego Tarrique, metió a nombre del oidor Antonio Maldonado el dinero recabado por las composiciones a la Real Caja de México: AGI, Contaduría, 695 A, $1594-1596$. RODRÍGUEZ VicEnTE: op. cit. (nota 4), p. 534.

${ }^{38}$ AGI, México, 23, n. 33, 30 de abril de 1596; AGI, Contaduría 728, f. 164 (1626-1627).

39 AGNM, Indiferente Virreinal, caja 4802, exp. 35, mayo de 1638. Un ejemplo de solicitación puede verse en: AGNM, Indiferente Virreinal, caja 3066, exp. 10.

${ }^{40}$ AGI, México, 71, R. 9, n. 116, 4 de abril de 1595; AGI, México, 71, R.10, n. 133. Cartas de la Audiencia, 28 de abril de 1596. Escribe el oidor Maldonado: "En el reino de la Galicia no ha tratado hasta ahora que yo haya sabido cosa contra extranjeros". El primer ingreso en la caja de Guadalajara por concepto de composiciones de extranjeros se registra en 1607. Tepaske, John J., KLeIn, Herbert S. y otros: The Royal Treasuries of the Spanish Empire in America, Durham, Duke University Press, 1990. Para el caso de Perú ver Rodríguez Vicente: op. cit. (nota 4), p. 534. 
Desde la capital virreinal se despachaban órdenes a las justicias de las provincias para que localizaran a los extranjeros residentes en sus jurisdicciones, pusieran sus bienes en resguardo y, de ser necesario, los enviaran a la cárcel de corte de la ciudad de México $^{41}$. En 1625, se crearon además siete comisiones integradas por un juez y un escribano para recorrer todo el territorio de la Audiencia de México, donde debían ser auxiliados por las autoridades locales para realizar su trabajo. Los foráneos que vivían en esos puntos apartados de la corte, estaban obligados a depositar una fianza correspondiente a la mitad del total de sus bienes como garantía de que se personarían veinte días más tarde con el virrey para concluir su proceso. Todo indica que comisiones como éstas se formaron hasta 1672, año en que Mariana de Austria autorizó a los gobernadores realizar las composiciones y expedir las licencias en su nombre, de forma que todo el proceso podía realizarse en las provincias sin necesidad de viajar a la ciudad de México ${ }^{42}$.

En 1688 el octavo conde de Galve, Gaspar de la Cerda Sandoval, mandó se compusieran también a los naturales de los reinos de España que hubieran pasado sin licencia ${ }^{43}$.

\section{NACIÓN, CALIDAD Y HACIENDA: LOS SUJETOS DE LA GRACIA}

Las instrucciones enviadas por Felipe II llegaron a los virreinatos del Perú y de la Nueva España en 1592. Su aplicación, sin embargo, se realizó de forma dispareja según las condiciones particulares en cada jurisdicción. Así, por ejemplo, en Cartagena de Indias se ejecutaron en 1593 en la isla de Margarita, en Lima y Quito hasta 1594 por causa de la inestabilidad creada por la revolución de las Alcabalas ${ }^{44}$. En México se aplazaron hasta 1595 , pero no por razones políticas sino porque el virrey Luis de Velasco y los oidores de la Audiencia necesitaron aclaraciones del Consejo de Indias para entender cómo someter a una población tan amplia y variada a una iniciativa que parecía no contemplar diferencias entre las distintas naciones o en las relaciones que cada una de ellas mantenía con el monarca ${ }^{45}$. Dudas similares fueron remitidas desde el Perú al poco tiempo de haberse echado a andar las comisiones, lo cual indica que los gobiernos indianos entendían que la aplicación del arbitrio era un tema delicado que debía manejarse con mucha "blandura y suavidad" para no despertar animosidades ${ }^{46}$.

Un ejemplo de la confusión para discernir contra cuáles extranjeros debía usarse la medida se dio justamente en Perú donde en un inicio se había procedido contra los baleares, aunque pronto se reconoció su pertenencia al reino de Aragón y se les dejó

${ }^{41}$ Ver "Sentencia de juicio de residencia contra el conde de Monterrey" en Hanke, Lewis: Los virreyes españoles en América durante el gobierno de la casa de Austria, México, Madrid, 1976-1978, pp. 242-246.

42 AGNM, Reales Cédulas Duplicadas, vol. 30, exps. 53 y 54, ff. 84-85, 6 de agosto de 1672.

43 LAZA ZERón: op. cit. (nota 4).

44 Para el caso de Cartagena ver Vila Vilar: op. cit. (nota 4). Para el caso de la Isla Margarita: AGI, Contaduría, 1664 B. Rodríguez Vicente: op. cit. (nota 4); Ortiz de la Tabla y Ducasse: op. cit. (nota 4).

45 Las primeras recaudaciones por composiciones entraron en la Caja Real de México el 18 de marzo de 1595 : AGI, Contaduría, 695 A. Cuentas de los Oficiales Reales de México, 1594-1596.

46 AGI, México, 23, n. 4, 30 de enero de 1595; AGI, México, 71, R.9, n. 116, 4 de abril de 1595. 
en paz. Asimismo, tuvieron dudas sobre si debían incluir a los naturalizados en Castilla, a los hijos de extranjeros nacidos en la Península o a aquellos que teniendo licencia para tratar y contratar se habían establecido en América. En la Nueva España, por otro lado, se entendía que por los derechos de señoreaje adquiridos por la reciente anexión de Portugal a la Monarquía (1580), los lusitanos se habían convertido en naturales, mientras que otros vasallos del rey, como los flamencos y los italianos, alegando esos mismos derechos también la podían llegar a solicitar. El Consejo de Indias señaló entonces que se sancionara a todos los extranjeros que hubiesen pasado sin licencia subrayando de esa forma que la ofensa contra el rey era haber violado sus ordenanzas en materia de migración y no en sí el origen de las personas aunque, en realidad, ésa era la razón primaria que sustentaba el arbitrio ${ }^{47}$.

Las autoridades virreinales reiteraron la pertinencia de dar ciertas concesiones con los vasallos del rey. En el Perú se instruyó hacerles "alguna comodidad más que a los otros", expresión que puede ser entendida en términos monetarios pero también honoríficos. Un ejemplo de favoritismo lo encontramos en México aplicado a los portugueses, por lo menos hasta la firma del tratado de Lisboa en 1668. El virrey Luis de Velasco insistió sobre sus derechos de naturaleza hasta 1593 y la comisión formada por el marqués de Guadalcázar decidió suspender sus causas en 1615, argumentando que no se daba abasto con el trabajo que tenía despachando los asuntos de las otras naciones. Más significativo resulta "la comodidad" que les hizo el virrey Rodrigo Pacheco, marqués de Cerralvo, al emitir el bando para llamar a composiciones distinguiendo entre "extranjeros y naturales de la corona de Portugal" en 1625, o la diferencia nominal usada durante la Guerra de Restauración cuando se optó por componer extranjeros y pedir donativo gracioso a los lusitanos, aunque en realidad todos se sometían al mismo procedimiento ${ }^{48}$.

Un trato aún más favorable recibían los irlandeses a finales del siglo XVII a quienes los jueces, por su "calidad y religión", los exentaban del proceso de la composición, aunque se les requerían donativos y por lo general se les incluía en la prohibición de vivir en los puertos y reales de minas ${ }^{49}$. Otras naciones como los algaravíos, las procedentes de la península itálica o incluso los griegos, recibieron también privilegios a través de solicitaciones o pleitos que describiremos más adelante.

Por el contrario, la Corona dispuso una relación hostil contra los naturales de los Países Bajos aunque en la práctica no tuvo mucho efecto. En 1607, dos años antes que

\footnotetext{
47 AGI, México, 22, n. 83 (1592); AGI, Lima, 570, f. 252v, 13 de enero de 1595

48 AGI, México, 22, n. 112, 25 de febrero de 1593; AGI, México, 28, n. 23, 25 de mayo de 1615; AGI, México, 29, n. 26, 27 de octubre de 1619; AGNM, General de Parte, vol. 9, exp. 120, f. 80, 18 de julio de 1643. Sirva de ejemplo el caso de los portugueses Juan Bello y Manuel de Acosta, que dijeron en 1654 "haberse compuesto atento de que los 30 pesos que había dado por vía de donativo con lo cual mandó se volviera al dicho fiscal para que concertare esta composición": AGNM, Reales Cédulas Duplicadas, vol. 48, exp. 399 (1654). Igualmente quedan registradas en las cuentas de los oficiales reales los ingresos diferenciados entre composiciones de extranjeros y donativos de portugueses. Ver TePASKe, John y KLEIN, Herbert: Ingresos y egresos de la Real Hacienda de Nueva España, México, Instituto Nacional de Antropología e Historia, 1988.

49 Por ejemplo a Juan Morfa, irlandés, se le declaró ser de los no comprendidos en el bando y se le dio licencia en 1674: AGI, México, 48, R. 1, n. 10, 24 de enero de 1676; a Dionisio Colines se le dio igualmente licencia cuando vieron que "era católico cristiano, de nación de las más favorecidas por la corona de Castilla por su integridad de fe puede permitírsele su residencia y comercio libre en dichos reinos": AGNM, Indiferente Virreinal, Caja 5897, exp. 30 (1694).
} 
se declarara la Tregua de los Doce Años, se buscó reprimir a los flamencos avecindados en América. Como parte de su estrategia para desgastar las redes comerciales de las siete provincias norteñas y para proteger los territorios orientales y occidentales de sus posibles ataques, Felipe III instruyó a sus virreyes hicieran una lista de todos los extranjeros que habitaban en los virreinatos y de entre ellos expulsaran únicamente a los neerlandeses. Pero ni la Audiencia de México ni la de Lima hicieron mayores esfuerzos en cumplimentar la orden, justificando su incapacidad de acción en la enormidad del territorio bajo su control, la importancia social o laboral de los flamencos o el mucho rigor que significaba una medida semejante para gente que era mayoritariamente artesanos o campesinos ${ }^{50}$. Para apoyar esta medida y restringir la presencia y actividades económicas de los neerlandeses en las colonias, la Corona prohibió desde 1615 se aceptara a los "septentrionales" a composición bajo ninguna circunstancia, aunque siguieron abundando las excepciones a lo largo del siglo XVII ${ }^{51}$.

De forma aún más áspera se reaccionó contra los franceses, sujetándolos a represalias en concordancia con las realizadas en la Península en 1625, 1635 y 1674, siendo éste uno de los colectivos tradicionalmente más castigados por la Corona española en ambos lados del Atlántico ${ }^{52}$.

Una de las dudas más recurrentes de los servidores indianos fue cómo proceder con los extranjeros pobres. Al contrario de lo que se había supuesto en Madrid por el informe del capitán Pedro Vivanco, los primeros meses de recaudaciones evidenciaron la verdadera cara de los migrantes europeos en las Indias: la mayoría eran "gente pobre y miserable que vive de su sudor y trabajo" situación que llevó a algún virrey a calificar el arbitrio de "mucho rigor" ${ }^{3}$. Para poder obtener cantidades significativas para la hacienda real, las comisiones tuvieron que permitir el pago de las composiciones en cuotas. Si bien esta solución se tradujo en mayores percepciones a largo plazo -algunos finiquitos de deuda contraída en 1597 no se terminaron de pagar sino hasta 1620-, también implicó la prorrogación de las comisiones y de los salarios de los comisionados ${ }^{54}$. Para evitar esos inconvenientes, a partir de 1619 se incluyó un párrafo en las instrucciones donde se recomendaba postergar las causas de quienes no tuvieran recursos suficientes

50 AGI, México, 27, n. 52; AGI, México, 26, n. 100, 6 de noviembre de 1606; AGI, Lima, 95.

51 AGI, México, 28, n. 23, 25 de mayo de 1615; AGNM, Indiferente Virreinal, caja 5195, exp. 25, 29 de abril de 1625; AGI, México, 48, R. 1, n. 10, 24 de enero de 1676. López MARTín, Ignacio: «Entre la guerra económica y la persuasión diplomática: el comercio mediterráneo como moneda de cambio en el conflicto hispano-neerlandés (15741609)», Cahiers de la Méditerranée, 71 (2005): http://cdlm.revues.org/index955.html [Consulta: 30 mayo 2011]; ISRAEL, Jonathan: «La guerra económica y la monarquía hispánica», en RUIZ MARTíN, Felipe: La proyección europea de la Monarquía Hispánica, Madrid, Editorial Complutense, 1996; SAlas Almela, Luis: «Poder señorial, comercio y guerra: Sanlúcar de Barrameda y la política de embargos de la Monarquía Hispánica, 1585-1641», Cuadernos de Historia Moderna, 33 (2008), pp. 35-59; Stols, Eddy: De Spanse Brabanders I, Bruselas, Paleis der Academiën, pp. 8-24. Para el caso de Perú ver Bradley, Peter T.: «El Perú y el mundo exterior. Extranjeros, enemigos y herejes (siglos XVI-XVII)», Revista de Indias, LXI/233 (2001), pp. 651-671. Thomas, Werner: La Represión contra el protestantismo en España, Bélgica, Leuven University Press, 2001.

${ }_{52}$ Alloza Aparicio: op. cit. (nota 25); Girard, Albert: El comercio francés en Sevilla y Cádiz en tiempos de los Habsburgo, Sevilla, Renacimiento, 2006; Thomas: op. cit. (nota 51), pp. 361-375.

53 AGI, México, 71, R. 9, n. 129, 18 de diciembre de 1595; AGI, México, 71, R. 9, n. 116, 4 de 1595; AGI, México, 23, n. 12, 6 de abril de 1595; AGI, México, 71, R.10, n. 133, 28 de abril de 1596; AGI, México, 28, n. 23, 25 de mayo 1615 .

54 AGNM, Archivo Histórico de Hacienda, vol. 425, exp. 2 (1596); AGNM, Indiferente Virreinal, caja 6220, exp. 8, 11 de agosto de 1625; AGI, Contaduría, 727, f. 184 (1625-1626). 
hasta que acumularan más caudal. Asimismo, se hicieron excepciones con personas físicamente imposibilitadas y con los adultos mayores ${ }^{55}$.

Otro asunto que requirió indicaciones especiales del Consejo de Indias fue el relativo a los procesados por el Santo Oficio. Los oidores expresaron muy pronto la sospecha y mala opinión que tenían sobre estos extranjeros, mayoritariamente ingleses, flamencos, alemanes y portugueses, por los "muchos inconvenientes y poca satisfacción" que tenían de ellos por su origen protestante y converso, pero el Consejo de Indias dejó en manos de los inquisidores determinar el futuro que debían correr los penitenciados y reconciliados con la Iglesia católica. Se entendía así mismo que las personas que renunciaban a su fe en favor de la católica perdían, en teoría, su vasallaje y por ello, el monarca los acogía como uno más de los suyos exentándoles de la composición en la mayoría de los $\operatorname{casos}^{56}$.

\section{LA RECEPCIÓN DE LA GRACIA: LA COMPOSICIÓN Y LA REACCIÓN DE LOS EXTRANJEROS}

Lejos de ser tomado como un arreglo ventajoso o positivo, para la mayoría de los extranjeros avecindados en las Indias la composición se vio como un agravio que el monarca les hacía por el simple hecho de no haber nacido en los reinos de España. Sus opiniones, expresadas con palabras que reflejan sentimientos de deslealtad, son rastros de la indignación causada por el desdén del rey a los lazos de vasallaje que lo unían a sus súbditos no hispanos y a lo que se consideraba una excesiva avaricia de su parte. En 1598, por ejemplo, el tonelero flamenco Alberto de Meyo se alegró de los triunfos alcanzados por el conde Mauricio de Nassau en los Países Bajos. Cuando los inquisidores le preguntaron la razón de su satisfacción Meyo replicó: "por los daños que han recibido de los españoles y que no los dejan vivir en paz y por haberle hecho pagar el rey cien pesos por ser extranjero". Enojado por la cantidad que le habían obligado a pagar, Meyo expuso a su paisano Jorge de Brujas sus deseos de residir en Zelanda, una de las provincias más beligerantes contra el rey de España durante la Guerra de los Ochenta Años. Brujas, quien a su vez había tenido que pagar trescientos pesos, apremió a su amigo a realizar el viaje y a avecindarse en una ciudad como Midelburgo "...en donde si tuviera cuatro reales no se los quitarían como en esta" 57 .

Según un informante, dos prisioneros portugueses hablaban en términos similares en la cárcel de la Perpetua acusando a Felipe II de tener:

...mala conciencia y quita las haciendas a sus vasallos y que ganó con traición el reino de Portugal... y que el secretario Antonio Pérez vino con treinta galeones de Dinamarca contra el rey y le hizo muy bien porque el rey quita las haciendas a los pobres portugue-

\footnotetext{
${ }^{55}$ AGNM, Reales Cédulas duplicadas, vol. 4, exp. 147, f. 170, 18 de mayo de 1619; AGNM, Indiferente Virreinal, caja 4638, exp. 34, 9 de diciembre de 1638; AGNM, Indiferente Virreinal, caja 5195, exp. 25, 29 de abril de 1625.

${ }^{56}$ AGI, México, 71, R. 9, n. 116, 4 de abril de 1595; AGI, México, 23, n. 12, 6 de abril de 1595; AGI, México, 71, R. 10, n. 133, 28 de abril de 1596; AGNM, Reales Cédulas Originales, vol. 14, exp. 9 y 10, ff. 33-42v, 12 de mayo de 1674.

57 AGNM, Inquisición, vol. 167, exp. 7 fs. 31 v. y 32 v. 1598-1601.
} 
ses y que los que vienen a las Indias a ganar un tomín les pide el rey cien pesos porque no pueden estar en ellas los extranjeros y que pueden quitar los leones de sus armas porque son gallinas... ${ }^{58}$

Entendiendo la gravedad del testimonio, el informante busca rectificar en la siguiente audiencia aclarando que no hablaban de Felipe II, sino del virrey don Luis de Velasco: "porque quitaba las haciendas a los pobres portugueses y las daba a su majestad el rey don Felipe... tomándoles cien pesos a cada uno de ellos y a los extranjeros diciendo que no pueden estar en su tierra..."59.

Las impresiones de los servidores reales enviadas a Madrid confirman el malestar y descontento de las disposiciones que se acataban "con mucha pesadumbre" ya que, dada la pobreza de la gente, sólo "con buenos medios y darles más espera" se componían ${ }^{60}$. Más que buscar obtener la licencia que les otorgaba la venia real para poder vivir en las Indias, los extranjeros hacían cualquier cosa para librarse del careo con las autoridades, pues resultaba una molestia y los sometía al señalamiento público. Algunos presentaban testimonios falsos sobre su verdadera naturaleza con ayuda de españoles. Por ejemplo, Juan Benítez sirvió como testigo de Francisco de Arizmendi para probar que era navarro, aunque en realidad era francés ${ }^{61}$. Llegó a suceder que los extranjeros simplemente no se presentaban ante las comisiones obligando a las autoridades a ofrecer prórrogas acompañadas de amenazas de cárcel y confiscación de bienes en caso de no obedecer al llamado ${ }^{62}$. Se observó también como antes de que las composiciones empezaran a realizarse en la Audiencia de Guadalajara, muchos se mudaron a ciudades como Zacatecas, donde sabían no serían molestados. Este recurso continuó creyéndose útil por lo menos hasta 1622, como lo demuestra el testimonio de Simón Luis, quien advirtió a un juez de comisión que no tenía jurisdicción para aprehenderlo por encontrarse en la Nueva Galicia ${ }^{63}$.

Pero para aquellos que no tenían posibilidad de moverse, la renuncia a una buena parte de su hacienda era prácticamente inevitable. En la Nueva España, al igual que en otros territorios indianos, las cantidades que por lo general se cobraron a los extranjeros fluctuaban entre los 20 y los 500 pesos, siendo los 100 pesos la suma que se introdujo con más frecuencia por ese concepto en las Cajas Reales ${ }^{64}$. La cortedad de los montos ha sido calificada anteriormente de "ridículos" ${ }^{65}$. Si bien es verdad que en comparación con otras recaudaciones esta consideración podría parecer adecuada, valdría la pena preguntarse lo que las exacciones representaban para la economía del extranjero penalizado. En 1641, Basilio Ruíz, un portugués casado y con un hijo, declaró que sus

\footnotetext{
58 AGNM, Inquisición, vol. 161, exp. 6 (1597).

59 Ibidem.

${ }^{60}$ AGI, México, 71, R.9, n. 116, 4 de abril de 1595; AGI, México, 71, R. 9, n. 129; AGI, México, 23, n. 12, 6 de abril de 1595 .

${ }^{61}$ AGNM, Indiferente Virreinal, 2300, exp. 7 (1629).

${ }^{62}$ AGNM, Indiferente Virreinal, caja 5195, exp. 25, 29 de abril de 1625.

${ }_{63}$ AGI, México, 71, R. 10, n.133, 28 de abril de 1596; AGNM, Inquisición, vol. 335, exp. 46, f. 209, noviembre de 1622

${ }^{64}$ AGI, Contaduría, 695 A; 705; 709; 712; 719; 722; 728; 735; 737. Para el Perú ver De la Tabla Ducasse: $o p$. cit. (nota 4); Vila Vilar: op. cit. (nota 4); Rodríguez Vicente: op. cit. (nota 4).

${ }^{65}$ Vila Vilar: op. cit. (nota 4), p. 6.
} 
únicos bienes eran un esclavo negro de Angola, seis cuadros de distintas hechuras, un caballo ensillado y un colchón, resultando su composición en cuarenta pesos. A Antonio Acosta, labrador algavariño, se le pedía también cuarenta pesos aunque su hacienda se reducía a una casa de paja vieja, un poco de ropa, una mula vieja ensillada y treinta pesos de oro común, todo valuado en ciento veinte pesos. Inocencio Semino, genovés, casado y con cuatro hijos declaró tener un caudal que alcanzaba los trescientos pesos, de donde se determinó que debía pagar cien. El portugués Juan Bello tenía un patrimonio de doscientos pesos, pero perdió una gran parte en el salario de su letrado y el pago de su carcelería cuando su comparecencia ante los jueces de comisión se complicó en 1654. Aún así, se vio obligado a pagar cien pesos. Desde esta perspectiva, se entiende que enfrentarse a una composición significaba, para la mayoría de los extranjeros, una verdadera desgracia que los ponía en una situación de incertidumbre por no saber el efecto que su comparecencia ante los jueces podía llegar a tener en los bienes que hasta entonces habían acumulado y que, ahora sabemos, podía significar una tercera parte o más de su patrimonio ${ }^{66}$.

La pérdida de caudal no era el único inconveniente. Las incomodidades se sumaron con el paso de los años cuando las composiciones se hicieron más rutinarias. Cada vez que se publicaba un bando exigiendo la presencia de los foráneos ante las autoridades, éstos debían presentar cualquier licencia que los respaldara, incluyendo las que se habían obtenido por medio de la composición con sus posteriores apostillas o cualquier otro tipo de merced que tuvieran en su poder. No obstante, entre uno y otro bando podían pasar años e incluso décadas, lo que significaba que el extranjero debía guardar sus papeles en lugares seguros. Pero la movilidad, el descuido, los accidentes o los desastres naturales podían acabar con las únicas pruebas que los amparaban. También llegó a suceder que los jueces de comisión retuvieran los originales de las licencias obligando a los propietarios a exigir su devolución o pedir traslados en la ciudad de México ${ }^{67}$.

Los originales eran también el único resguardo del extranjero para evadir las molestias y extorsiones que les infringían las autoridades locales y la Santa Hermandad, sobre todo en las provincias, aunque en muchos casos ni siquiera la licencia del rey resultaba suficiente. Varios extranjeros solicitaron al virrey que les otorgara amparos en donde se ordenara a sus subordinados cesasen de vejarlos ${ }^{68}$. Estas incomodidades no las sufrían exclusivamente los foráneos; los gallegos y catalanes también pasaban por todo tipo de inconvenientes porque eran "confundidos" con portugueses o franceses, por cuanto no pocos tuvieron que solicitar el mismo tipo de recaudos para que las justicias no procedieran en su contra ${ }^{69}$.

${ }^{66}$ AGNM, Indiferente Virreinal, caja 3263, exp. 27, 30 de junio de 1638; AGNM, Marina, vol. 1, exp. 7, ff. 3255, enero de 1641; AGNM, Indiferente Virreinal, caja 68, exp. 5 (1641); AGNM, Reales Cédulas Duplicadas, vol. 48, exps. 399 a 401 (1654).

${ }^{67}$ AGNM, Indiferente Virreinal, caja 5195, exp. 25, 29 de abril de 1625; AGNM, Indiferente Virreinal, caja 3066, exp. 9, noviembre de 1638 .

${ }_{68}$ AGNM, Tierras, vol, 2961, exp. 122 (1610); AGNM, Indiferente Virreinal, caja 3066, exp. 9, noviembre de 1638; AGNM, Indiferente Virreinal, caja 5598, exp. 114, 16 de octubre de 1638; AGNM, Reales Cédulas originales, vol. 233, exp. 4, ff. 61-68v. (1641); AGNM, Reales Cédulas Duplicadas, vol. 18, exp. 100, f. 82, 10 de febrero de 1651; AGNM, Reales Cédulas Duplicadas, vol. 48, exp. 399-401 (1654).

${ }^{69}$ AGNM, Indiferente Virreinal, caja 5195, exp. 25, 29 de abril de 1625; AGNM, Indiferente Virreinal, caja 6528, exp. 59, 28 de enero de 1643; AGI, México, 48, R. 1, n. 10, 24 de enero de 1676. 
Para evadir pagar las composiciones los extranjeros se valieron de distintos recursos. Ciertas naciones reclamaron sus derechos de pertenencia a uno de los reinos de España para lograr su reconocimiento como naturales y no ser sujetos a penalización. Fue éste el caso de los sicilianos y los napolitanos que sostenían su pertenencia a la corona de Aragón y especialmente los algaraveños quienes, al parecer, ganaron el reconocimiento de su vínculo a la corona de Castilla en la Audiencia del Crímen de México cuando estalló la Guerra de Restauración portuguesa en $1640^{70}$. Caso curioso resulta el de dos cretenses, quienes aseguraban que la isla había sido siempre "señorío y dominio de los señores reyes de España" y haber sido ellos quienes la habían cedido a la república de Venecia. Ellos, como buenos cristianos y "leales vasallos" habían emigrado a la Península ibérica y de ahí a las Indias en 1644, cuando los otomanos invadieron su tierra. No todos estos casos resultaron en exención del pago, pero sí en importantes "comodidades" pecuniarias, muchas veces ganadas a través de la pericia del letrado en señalar argumentos en favor de la lealtad y el vasallaje de sus clientes, aunque éstos fueran parcialmente falsos ${ }^{71}$.

Para los extranjeros que se dedicaban al comercio, la composición era también perjudicial porque los constreñía a negociar en las Indias y les prohibía la participación en el comercio Atlántico o Pacífico. Aunque sabemos que de poco sirvieron estas restricciones para mantenerlos al margen de la contratación, es un hecho que los volvían vulnerables en caso de que las justicias reales decidieran actuar contra ellos ${ }^{72}$.

Aunque para la mayoría significó un problema, hubo también algunos extranjeros que aprovecharon su sometimiento a composición para solicitar otro tipo de mercedes como la habilitación para obtener oficios militares, licencias para poder vivir en las minas o puertos o para que se les declarara naturales de los reinos de Indias según lo estipulaban las cédulas de 1561 y 1562 . Estas naturalezas eran dadas por el virrey y no necesitaban ser refrendadas en Castilla si no se pretendía participar en el comercio transocéanico por vías lícitas ${ }^{73}$.

Por lo general, los extranjeros que se compusieron estaban avecindados, eran casados y desempeñaban una ocupación, lo que indica su integración en las comunidades locales. Fue ese arraigo lo que sirvió como fuerza de coacción que los orillaba a presentarse ante los jueces de comisión. Esta gente, ya establecida y con lazos sociales estables, no habían requerido una licencia del rey para migrar y asentarse en las Indias, por cuanto someterse a la composición, lejos de ser un instrumento de regularización que les beneficiara, era una penalización que los perjudicaba.

\footnotetext{
70 AGNM, Marina, vol. 1, exp. 7, ff. 32-55, enero de 1641; AGNM, Reales Cédulas Duplicadas, vol. 14, exp. 274, f. 196,1 de febrero de 1650 .

71 AGNM, Indiferente Virreinal, caja 5897, exp. 30 (1689-1698).

72 AGI, México, 28, N. 23, 25 de mayo de 1615; AGN, Indiferente Virreinal, caja 5897, exp. 30 (1694); AGNM, Indiferente Virreinal, caja 6112, exp. 25, 18 de febrero de 1694.

73 AGNM, Reales Cédulas Duplicadas, vol. 14, exp. 284, ff. 201-202, 22 de agosto de 1650; AGNM, Reales Cédulas Duplicadas, vol. 14, exp. 284, ff. 202-203, 17 de mayo de 1651; AGNM, Reales Cédulas Duplicadas, vol. 18, exp. 100, f. 82, 10 de febrero de 1651; AGNM, Reales Cédulas Duplicadas, vol. 14, exp. 273, ff.195-195v, 23 de diciembre de 1648 .
} 